\title{
Utilization of breast MRI and breast MRI- guided biopsy in clinical practice: results of a survey in Québec and France
}

\author{
Benoît Mesurolle ${ }^{1 *} \mathbb{D}$, Simon Sun ${ }^{2}$ and Michelle Zhang ${ }^{2}$
}

\begin{abstract}
Background: To investigate the practice regarding breast MRI exams and breast MRI-guided biopsies in two countries with different health care systems, France and Québec. A 12-item questionnaire was distributed online among radiologists from France and Québec, attempting to determine: demographic characteristics and breast MRI diagnostic and MRI-guided practices (indications, workload, availability, and waiting time assessment).

Results: One hundred and seventy radiologists (France, 132 respondents (28.5\%); Quebec, 38 respondents (35.2\%)) participated in the survey, most of them based in non-academic centers. Thirty-eight percent of Quebec and 2.3\% of French radiologists did not perform breast MRI in their daily practice. Nearly $50 \%$ of French and Quebec respondents interpreted 1-10 breast MRI exams per week. Decision-making factors of preoperative MRI were similar in both countries (pathology, age, and breast density), with a heavier emphasis placed on the surgeon's opinion in Quebec $(47.8 \%$ versus 21.8\% $(p=0.009)$ ). Quebec demonstrated a higher waiting time than France $(1-2$ weeks in $40 \%$ versus less than 1 week in 40\%). MRI-guided breast biopsies (less than 5 MRI-guided biopsies per week) were being performed by a minority of the respondents (36\% in France and $43 \%$ in Québec).

Conclusion: Most of radiologists performing breast MRIs work in non-academic institutions in both countries. Waiting time is higher in Quebec, but most of preoperative breast MRIs are performed within 3 weeks in both countries. The surgeon plays an important role in recommending preoperative MRI in Quebec. MRI-guided breast biopsies are not widely available in both countries.
\end{abstract}

Keywords: Breast MRI, Breast MRI-guided biopsy, Survey, Healthcare system, France, Québec

\section{Key points}

- Half of French and Quebec radiologists interpret 110 breast MRI exams per week

- MRI-guided breast biopsies are not widely available in both countries

- Quebec demonstrates a higher waiting time than France for breast MRI exams

- Most of preoperative breast MRIs are performed within 3 weeks in both countries

\footnotetext{
* Correspondence: bmesurolle@yahoo.fr

${ }^{1}$ Centre République, ELSAN, 99 avenue de la République, BP 304, 63023

Clermont-Ferrand Cedex 2, France

Full list of author information is available at the end of the article
}

- Surgeon's opinion influences recommendation of preoperative MRI in Quebec

\section{Background}

While mammography and breast ultrasound remain the standard breast imaging modalities, breast magnetic resonance imaging (MRI) has also become important for the detection of breast carcinoma [1,2]. Recently, its indications have dramatically increased, including screening, diagnosis, and staging [2]. However, breast MRI indications vary among radiologists and among hospitals, given the general lack of consensus [3], and its use as a preoperative staging tool remains a controversial topic [4].

\section{Springer Open}

() The Author(s). 2020 Open Access This article is licensed under a Creative Commons Attribution 4.0 International License, which permits use, sharing, adaptation, distribution and reproduction in any medium or format, as long as you give appropriate credit to the original author(s) and the source, provide a link to the Creative Commons licence, and indicate if changes were made. The images or other third party material in this article are included in the article's Creative Commons licence, unless indicated otherwise in a credit line to the material. If material is not included in the article's Creative Commons licence and your intended use is not permitted by statutory regulation or exceeds the permitted use, you will need to obtain permission directly from the copyright holder. To view a copy of this licence, visit http://creativecommons.org/licenses/by/4.0/. 
In particular, breast MRI carries the risk of potentially lengthening surgical waiting times due to its propensity to create the need for second-look ultrasounds, with or without associated biopsy, along with increasing mastectomy rates [5-7].

Therefore, the purpose of the present study was to identify practice trends and opinions concerning breast MRI and MRI-guided biopsies in two different health care systems, one in a European (France) and the other in a North American country (Province of Quebec/ Canada).

\section{Methods}

From September 2015 to September 2016, a web-based survey was conducted with members of the SCFR ("Société Canadienne Française de Radiologie", Québec, Canada) and SIFEM ("Société d'Imagerie de la Femme", France) targeting radiologists involved in breast imaging. Names and e-mail addresses were obtained from the publicly available membership lists of these two radiological professional organizations. The web-based survey was administered via SurveyMonkey. Radiologists were contacted and asked to voluntarily complete an anonymous survey within 4 weeks; a single follow-up e-mail was sent a few weeks later to remind radiologists of the ongoing survey. A 12-item questionnaire was designed in which respondents were asked to choose a single best response for each question, except for one instance where multiple choices could be made (Table 1).

The survey was comprised of four sections (Table 1): (1) personal practice characteristics (e.g., physician age and type of practice), (2) characteristics of the breast MRI exams (e.g., preoperative MRI indication, factors influencing their recommendation), (3) availability of MRI-guided breast biopsies and their frequency, and (4) waiting time of breast MRI in their respective institutions. All questions and answers are detailed in Tables 2, 3, 4, 5, and 6 .

\section{Breast MRI indications and numbers (questions 3, 4, and} 12)

The purpose of these questions was to determine the number of breast MRI exams performed per week and the proportion of preoperative breast MRI in their practice. The reasons justifying their recommendations of breast MRI were also investigated.

\section{MRI-guided biopsies (questions 5 and 6)}

The purpose of these questions was to determine if radiologists had the possibility of performing MRI-guided biopsies in their institution, and if so, to evaluate the number of biopsies performed per week.

\section{Waiting time breast MRI (questions 7, 8, 9, 10, and 11)}

The purpose of these questions was to assess the waiting time for breast MRI in the institution of the responding radiologists. Breast MRI waiting time was defined as time from initiation of the request for breast MRI to the date of the actual breast MRI.

\section{Statistical analysis}

Descriptive results were summarized in tables and presented as counts and percentages with 95\% confidence interval. $\chi^{2}$ tests were used for categorical variables. All tests were two-sided, with the alpha significance level set at less than 0.05. Data was analyzed using SPSS (version 21.0, released 2011, Armonk, NY: IBM Corp).

\section{Results}

\section{Response rate}

In France, 132 of 463 radiologists (28.5\%) responded, whereas in Quebec, 38 out of 108 radiologists responded (35.2\%).

\section{Demographics (questions 1 and 2)}

The characteristics of the study population are shown in Table 2. Most of the responding radiologists were "senior" radiologists, $74 \%$ aged between 40 and 59 in Québec and 66\% aged between 40 and 59 in France. The three types of surveyed hospitals included academic medical centers, private clinics, and local community hospitals. Most radiologists were employed in nonacademic institutions (i.e., general hospitals in Quebec, and private institutions in France).

\section{Breast MRI number, indications, and factors influencing recommendation of preoperative breast MRI (questions 3, 4, and 12) (Tables 3 and 6)}

In Québec, 38\% of respondents were not performing any breast MRI, whereas $49 \%$ performed between 1 and 21 breast MRI exams per week (mostly 1-10). In France, $75 \%$ of respondents performed between 1 and 19 MRI exams per week. There were significantly more radiologists in France performing between 10 and 19 breast MRI examinations per week than in Québec (27.3\% versus $2.7 \%, p=0.001)$. For the majority of radiologists in both countries, preoperative breast MRI exams were not the main clinical indication (representing less than 25\% of breast MRI exam indications for $41 \%$ of respondents in France and $61.9 \%$ in Québec).

In both countries, the 3 most important decisionmaking factors for performing a preoperative breast MRI were found to be the pathologic features of breast carcinoma, followed by age and breast density. In Québec, the surgeon's preference was a vital factor for $47.8 \%$ of the performed breast MRIs, as opposed to $21.8 \%$ in France $(p=0.006)$ (Table 6). 
Table 1 breast MRI survey

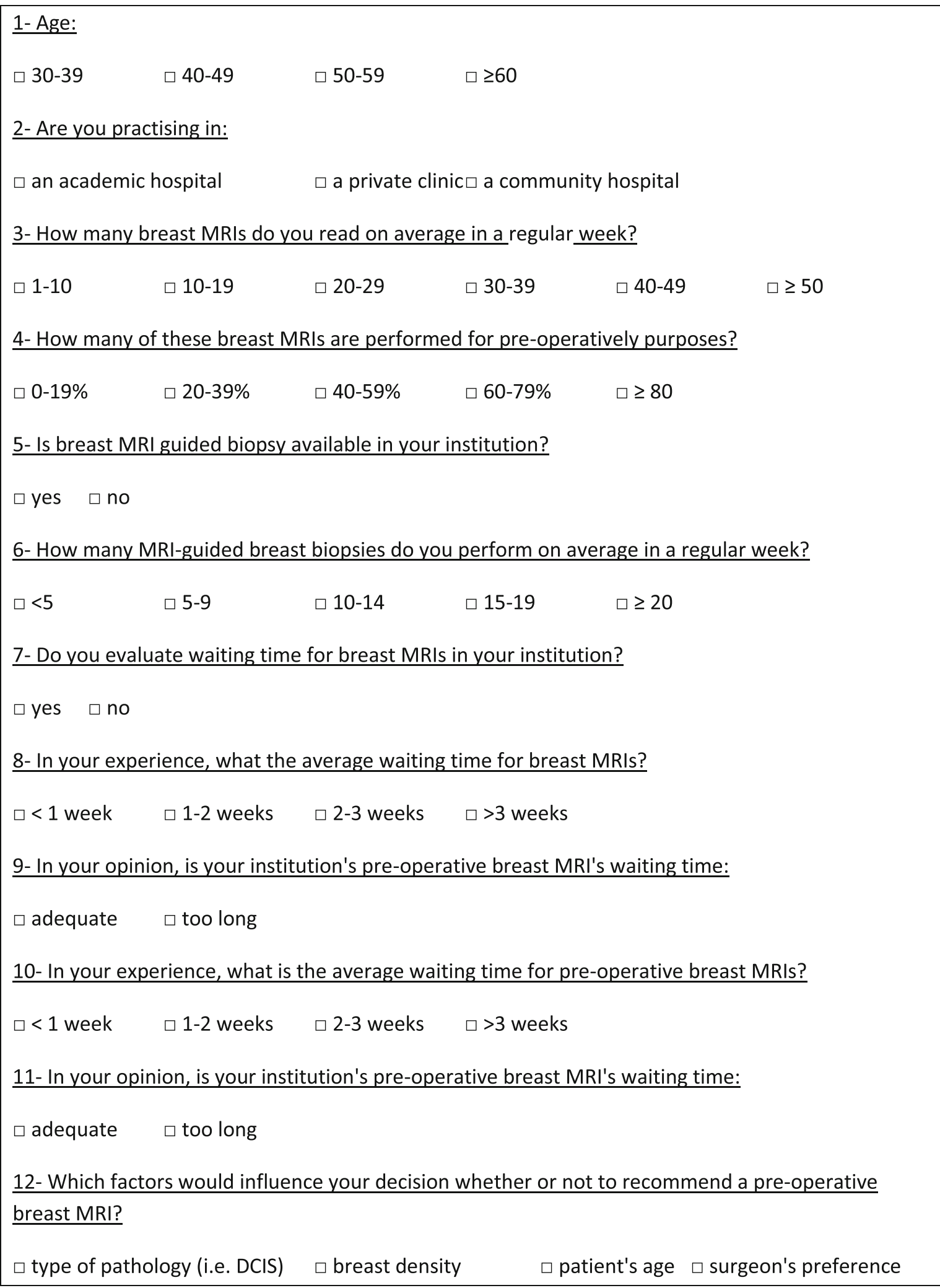


Table 2 General information

\begin{tabular}{|c|c|c|c|c|c|}
\hline & \multicolumn{2}{|l|}{ Québec } & \multicolumn{2}{|l|}{ France } & \multirow{2}{*}{$\begin{array}{l}p \text { value } \\
x^{2} \text { test }\end{array}$} \\
\hline & Proportions & $95 \% \mathrm{Cl}$ & Proportions & $95 \% \mathrm{Cl}$ & \\
\hline \multicolumn{6}{|l|}{ Age (years) } \\
\hline$<30$ & $0 \%(0 / 38)$ & {$[0-0]$} & $0.8 \%(1 / 132)$ & {$[0-2.3]$} & 0.590 \\
\hline $30-39$ & $18.4 \%(7 / 38)$ & {$[5.5-31.3]$} & $18.9 \%(25 / 132)$ & {$[12.2-25.7]$} & 0.943 \\
\hline $40-49$ & $47.4 \%(18 / 38)$ & {$[30.7-64]$} & $28.8 \%(38 / 132)$ & {$[22-36.6]$} & 0.032 \\
\hline $50-59$ & $26.3 \%(10 / 38)$ & [11.6-41] & $37.1 \%(49 / 132)$ & {$[28.8-45.5]$} & 0.218 \\
\hline$\geq 60$ & $7.9 \%(3 / 38)$ & {$[1.1-16.88]$} & $14.4 \%(19 / 132)$ & {$[8.3-21.5]$} & 0.293 \\
\hline Academic hospital & $26.3 \%(10 / 38)$ & [11.6-41] & $16.7 \%(22 / 132)$ & {$[10.2-23.1]$} & 0.180 \\
\hline Private clinic & $63.2 \%(24 / 38)$ & {$[47.1-79.2]$} & $22.2 \%(28 / 132)$ & {$[14.1-28.3]$} & $<0.0001$ \\
\hline Community hospital & $10.5 \%(4 / 38)$ & {$[0.3-21.7]$} & $62.1 \%(82 / 132)$ & {$[53.7-70.5]$} & $<0.0001$ \\
\hline
\end{tabular}

Note-Data in parentheses are ratio

MRI-guided biopsies (questions 5 and 6) (Table 4)

MRI-guided breast biopsy was not being performed at most of the surveyed radiological practices $(64 \%$ in France and 57\% in Québec). And when MRI-guided biopsy was an available procedural option, they were being performed less than 5 per week.

\section{Waiting time breast MRI (questions 7, 8, 9, 10 and 11) (Table 5)}

In both countries, most facilities kept track of their MRI waiting time, with up to $68 \%$ of institutions in France and $80 \%$ in Québec performing audits. In Québec, waiting time was greater than 3 weeks in $55 \%$ of respondents $(p<0.001)$ whereas it was never reported as less than 1 week. In France, waiting time was between 1 and 2 weeks for $44.5 \%$ of respondents $(p=0.001)$ and was less than 1 week for $16.8 \%$ of respondents. In both countries, this waiting time was considered appropriate for most respondents.

With respect to preoperative breast MRI exams, $92.4 \%$ were performed within 2 weeks in France versus $45 \%$ in Québec. Indeed, $40.3 \%$ of respondents were able to perform them within 1 week in France, as opposed to 5\% in Québec $(p=0.002)$ and $52.1 \%$ within 1 to 2 weeks in France and $40 \%$ in Québec. No preoperative breast exams in France had to wait for more than 3 weeks ( $p=$ $0.001)$.

\section{Discussion}

The results of this study provide an interesting overview of breast MRI practices of radiologists in Québec and France, highlighting the differences between these two different organizational health care systems $[8,9]$.

Table 3 Breast MRI examinations

\begin{tabular}{|c|c|c|c|c|c|}
\hline & \multicolumn{2}{|l|}{ Québec } & \multicolumn{2}{|l|}{ France } & \multirow{2}{*}{$\begin{array}{l}p_{2} \text { value } \\
x^{2} \text { test }\end{array}$} \\
\hline & Proportions & $95 \% \mathrm{Cl}$ & Proportions & $95 \% \mathrm{Cl}$ & \\
\hline \multicolumn{6}{|c|}{ Number of examinations per week } \\
\hline None & $37.8 \%(14 / 37)$ & {$[22.4-54.2]$} & $2.3 \%(3 / 128)$ & {$[0.3-5]$} & $<0.0001$ \\
\hline $1-10$ & $46 \%(17 / 37)$ & {$[29.1-62.8]$} & $47.7 \%(61 / 128)$ & {$[38.9-56.4]$} & 0.854 \\
\hline $10-19$ & $2.7 \%(1 / 37)$ & {$[2.8-8.2]$} & $27.3 \%(35 / 128)$ & {$[19.5-35.2]$} & 0.001 \\
\hline $21-29$ & $5.4 \%(2 / 37)$ & {$[2.2-13.1]$} & $10.2 \%(13 / 128)$ & {$[4.8-15.5]$} & 0.376 \\
\hline$\geq 30$ & $8.1 \%(3 / 37)$ & {$[1.1-17.3]$} & $12.5 \%(16 / 128)$ & [6.7-18.3] & 0.461 \\
\hline \multicolumn{6}{|c|}{ Number of preoperative examinations } \\
\hline $0-24 \%$ & $61.9 \%(13 / 22)$ & {$[39.2-84.6]$} & $41 \%(50 / 122)$ & [32.1-49.8] & 0.096 \\
\hline $25-49 \%$ & $19 \%(4 / 22)$ & {$[0.7-37.4]$} & $36.9 \%(45 / 122)$ & {$[28.2-45.6]$} & 0.139 \\
\hline $50-74 \%$ & $4.8 \%(1 / 22)$ & {$[5.2-14.7]$} & $13.1 \%(16 / 122)$ & {$[7.0-19.2]$} & 0.468 \\
\hline$\geq 75 \%$ & $4.8 \%(1 / 22)$ & {$[5.2-14.7]$} & $4.1 \%(5 / 122)$ & {$[7.0-19.2]$} & 1.000 \\
\hline Unsure & $9.5 \%(2 / 22)$ & {$[4.2-23.2]$} & $4.9 \%(6 / 122)$ & {$[1.0-8.8]$} & 0.396 \\
\hline
\end{tabular}


Table 4 Breast MRI-guided biopsies

\begin{tabular}{|c|c|c|c|c|c|}
\hline & \multicolumn{2}{|l|}{ Quebec } & \multicolumn{2}{|l|}{ France } & \multirow{2}{*}{$\begin{array}{l}p_{\text {value }} \text { valu } \\
x^{2} \text { test }\end{array}$} \\
\hline & Proportions & $95 \% \mathrm{Cl}$ & Proportions & $95 \% \mathrm{Cl}$ & \\
\hline \multicolumn{6}{|c|}{ Breast MRI-guided biopsy availability } \\
\hline Yes & $42.9 \%(9 / 22)$ & {$[19.8-65.9]$} & $36.1 \%(44 / 122)$ & {$[27.4-44.7]$} & 0.552 \\
\hline \multicolumn{6}{|c|}{ Number of breast MRI-guided biopsies per week } \\
\hline$<5$ & $100 \%(9 / 9)$ & {$[100-100]$} & $97.7 \%(43 / 44)$ & {$[93.1-100]$} & 0.648 \\
\hline
\end{tabular}

\section{Response rate demographics (questions 1 and 2)}

This survey achieved a response rate of nearly 30\% (170/ 571) which corresponds to a good response rate within the reasonable expectations of an internet survey, usually achieving below $50 \%[6,10]$.

Contrary to Clauser et al.'s study where more than $50 \%$ of European breast radiologists were based in academic centers, most of the respondents in our study worked instead in non-academic institutions [6]. A comparison of French versus Quebec respondents showed that the majority of French breast radiologists were based in private centers whereas Quebec breast radiologists were mostly based in community hospitals. This reflects the different structural organizations between both health care systems, since the private medical sector in
Quebec is frequently "entirely" private as opposed to the French system which is still affiliated with the public health system (not "stricto sensu" private) $[8,9]$. As a result, only a minority of breast radiologists in Quebec are based in private institutions and most are practicing in community hospitals, as was noted in our survey.

Breast MRI examination numbers, indications, and factors influencing recommendation of preoperative breast MRI (questions 3, 4, and 12)

A significant number of respondents in Québec (38\%) were not performing any breast MRI as opposed to 2.3 $\%$ of respondents in France. A different organizational pattern might explain these numbers. Whereas breast MRIs can be performed in non-"breast" specialized imaging departments in France without specific prerequisite for radiologists interpreting these examinations, breast MRIs are usually performed by radiologists working in specialized centers named Designated Reference Center for Investigations ("Centre de Référence pour Investigation Désigné" (CRID)) in Québec. This type of practice is in accordance with the concept of "Breast Imaging Centers of Excellence" promoted by the American College of Radiology [11].

Table 5 Waiting time audit and estimated waiting time

\begin{tabular}{|c|c|c|c|c|c|}
\hline & \multicolumn{2}{|l|}{ Québec } & \multicolumn{2}{|l|}{ France } & \multirow{2}{*}{$\begin{array}{l}p \text { value } \\
x^{2} \text { test }\end{array}$} \\
\hline & Proportions & $95 \% \mathrm{Cl}$ & Proportions & $95 \% \mathrm{Cl}$ & \\
\hline \multicolumn{6}{|c|}{ Auditing waiting time } \\
\hline Yes & $80 \%(16 / 21)$ & {$[60.8-99.2]$} & $68.1 \%(81 / 119)$ & {$[59.6-76.6]$} & 0.282 \\
\hline \multicolumn{6}{|c|}{ Average waiting time breast MRI } \\
\hline$<1$ week & $0 \%(0 / 21)$ & {$[0-0]$} & $16.8 \%(21 / 119)$ & {$[10-23.6]$} & 0.048 \\
\hline $1-2$ weeks & $5 \%(1 / 21)$ & {$[5.5-15.5]$} & $44.6 \%(53 / 119)$ & {$[35.5-53.6]$} & 0.001 \\
\hline $2-3$ weeks & $25 \%(5 / 21)$ & {$[4.2-75.8]$} & $25.2 \%(30 / 119)$ & {$[17.3-33.1]$} & 0.984 \\
\hline$>3$ weeks & $55 \%(11 / 21)$ & {$[31.1-78.9]$} & $12.6 \%(15 / 119)$ & {$[6.5-18.7]$} & $<0.0001$ \\
\hline Unsure & $15 \%(3 / 21)$ & {$[2.1-32.1]$} & $0.8 \%(1 / 119)$ & {$[0.8-2.5]$} & $<0.0001$ \\
\hline \multicolumn{6}{|c|}{ Waiting time breast MRI opinion } \\
\hline Adequate & $68.4 \%(13 / 19)$ & {$[45.4-91.4]$} & $72 \%(85 / 118)$ & {$[63.8-80.2]$} & 0.746 \\
\hline Too long & $31.6 \%(6 / 19)$ & {$[8.6-54.6]$} & $28 \%(33 / 118)$ & {$[19.7-36.2]$} & 0.746 \\
\hline \multicolumn{6}{|c|}{ Average waiting time preoperative breast MRI } \\
\hline$<1$ week & $5 \%(1 / 21)$ & {$[5.5-15.5]$} & $40.3 \%(48 / 119)$ & {$[31.4-49.3]$} & 0.002 \\
\hline $1-2$ weeks & $40 \%(8 / 21)$ & {$[16.5-63.5]$} & $52.1 \%(62 / 119)$ & {$[43-61.2]$} & 0.317 \\
\hline 2-3 weeks & $30 \%(6 / 21)$ & {$[8-52]$} & $6.7 \%(8 / 119)$ & {$[2.2-11.3]$} & 0.001 \\
\hline$>3$ weeks & $10 \%(2 / 21)$ & {$[4.4-24.4]$} & $0 \%(0 / 119)$ & {$[0-0]$} & 0.001 \\
\hline Unsure & $15 \%(3 / 21)$ & {$[2.1-32.1]$} & $0.9 \%(1 / 119)$ & {$[0.8-2.5]$} & $<0.0001$ \\
\hline \multicolumn{6}{|c|}{ Waiting time preoperative breast MRI opinion } \\
\hline Adequate & $85 \%(17 / 21)$ & {$[67.8-102.1]$} & $81.5 \%(97 / 119)$ & {$[74.4-88.6]$} & 1.000 \\
\hline Too long & $15 \%(3 / 21)$ & {$[2.1-32.1]$} & $18.5 \%(22 / 119)$ & {$[11.4-25.6]$} & 1.000 \\
\hline
\end{tabular}

Note-Data in parentheses are ratio 
Table 6 Most important factors influencing your decision as to whether or not to recommend a preoperative breast MRI? (select all applicable choices)

\begin{tabular}{|c|c|c|c|c|c|}
\hline & \multicolumn{2}{|l|}{ Québec } & \multicolumn{2}{|l|}{ France } & \multirow{2}{*}{$\begin{array}{l}p \text { value } \\
x^{2} \text { test }\end{array}$} \\
\hline & Proportions & $95 \% \mathrm{Cl}$ & Proportions & $95 \% \mathrm{Cl}$ & \\
\hline Pathology (i.e., invasive vs. DCIS) & $78.3 \%(18 / 23)$ & {$[60-96.5]$} & $87.2 \%(109 / 125)$ & {$[81.3-93.1]$} & 0.259 \\
\hline Patient age & $52.2 \%(12 / 23)$ & {$[30.1-74.3]$} & $62.4 \%(78 / 125)$ & {$[53.8-71.0]$} & 0.356 \\
\hline Breast density & $47.8 \%(11 / 23)$ & {$[25.7-69.9]$} & $46.4 \%(58 / 125)$ & {$[37.5-55.3]$} & 0.900 \\
\hline Surgeon's preference & $47.8 \%(11 / 23)$ & {$[25.7-69.9]$} & $21.8 \%(26 / 125)$ & {$[13.6-28.0]$} & 0.006 \\
\hline MRI availability & $13 \%(3 / 23)$ & {$[1.85-27.9]$} & $4.8 \%(6 / 125)$ & {$[1-8.6]$} & 0.128 \\
\hline Other & $13 \%(3 / 23)$ & [1.85-28] & $22.6 \%(27 / 125)$ & {$[14.3-28.9]$} & 0.348 \\
\hline
\end{tabular}

Note-Data in parentheses are ratio

The number of breast MRI examinations performed by radiologists per week was found to be grossly similar in both countries. Most of the respondents performed 1-10 cases per week, with a substantial number performing 10-21 cases per week in France. These numbers are in agreement with numbers reported in a survey published in 2007 by Bassett, reporting that a majority of respondents (82\%) performed 1-15 cases per week in the USA [12].

Indications for performing preoperative breast MRI are still debatable with a recent tendency to decrease preoperative staging breast MRI exams, particularly in the absence of high-level evidence from randomized controlled trials demonstrating benefits of breast MRI in terms of survival $[3,13]$. Despite a lack of consensus as noted by several authors [3, 4], criteria employed to recommend preoperative breast MRI exams were consistent both within and also between both countries. Unsurprisingly, in both countries, the three most frequently cited variables considered for breast MRI in patients with newly diagnosed breast cancer were pathologic features, age, and breast density [3, 5]. Of particular note, the surgeon's opinion was also an important consideration in Québec, much more so than in France. Although this factor has not been extensively evaluated in recent studies [3, 5], it emphasizes the role of breast surgeons in the era of multidisciplinary approach, which is in agreement with Evidence-Based Medicine (EBM) guidelines [14]. Indeed, EBM integrates the best external evidence with individual clinical expertise and the patients' choices [14]. The role of the surgeon in patient selection for preoperative breast MRI has been recently evaluated by Lee et al. who noted that the decision to perform a preoperative breast MRI is multifactorial and takes into account many patient and tumor-related variables, all of which are weighed at the surgeons' "discretion" [15]. This significant difference between France and Québec could be explained by their different approach in breast cancer diagnosis, since French breast radiologists have a more extensive and involved role in providing results to patients and performing a preoperative workup before referring the patient to the surgeon $[16,17]$. In Québec, on the other hand, particularly in specialized "breast centers," patients are usually directly referred to the surgeons during the initial diagnosis of breast cancer [18], potentially explaining why the surgeon's opinion is weighed more heavily. The latter could also partly be related to Quebec's longer waiting times regarding breast MRI and therefore need to make a clinical decision before performing this examination.

\section{MRI-guided biopsies (questions 5 and 6)}

For nearly $100 \%$ of respondents in Québec and France, the estimated performed number of weekly MRI-guided biopsies was reported as 5 or less, which may at first glance appear quite low. However, these numbers are in agreement with a recent multi-centric retrospective French and Swiss study reviewing 1709 MRI-guided biopsies collected over a 7-year period in nine institutions, representing an average number of 27 biopsies per year, per institution [19].

Although essential because of the high sensitivity and limited specificity of breast MRI, MRI-guided biopsies are not widely available in both countries [20, 21]. While some authors consider the limited availability of breast MRI-guided biopsies "a serious weakness" limiting a more generalized usage of this modality [6], the low number of MRI-guided biopsies performed and the extra costs and requirements associated with this procedure (equipment, medical training, time-consuming procedure) could also contribute to explain the situation. In addition, as recommended by the American College of Radiology, an arrangement with affiliated facilities is an acceptable alternative ("In addition, facilities performing breast MRI must have the equipment to perform mammographic correlation, directed breast ultrasound, and MRI-guided intervention, or create a referral arrangement with a cooperating facility that could provide these services. The ACR strongly recommends that the cooperating facility be accredited by the ACR in breast MRI.") [22]. 
Waiting time for breast MRI (questions 7, 8, 9, 10, and 11) Extended wait times endured by patients are a rising and justified concern in our health care systems. This subject has historically been a more sensitive issue in Québec and Canada than in France [23, 24], likely due to the fact that although waiting times are audited in most institutions in both countries, this is more frequently done in Québec (80\% versus 68\%). Specifically, waiting times for breast MRI exams have been a particular source of concern [3]. Currently, Quebec governmental guidelines recommend a maximal delay of 90 days after reception of the first request whereas French recommendations based on "Plan Cancer 2014-2019" encourage a maximal average delay of 21 days [3, 25]. An audit from 2013 performed at the Centre Hospitalier de l'Université de Montréal showed that among 687 pending breast MRI requests identified at the end of September, 67\% exceeded recommended wait times, with $10 \%$ exceeding them by more than 12 months [3].

The impact of preoperative MRI on surgical waiting time has been explored through several recent publications [5, 24, 26-28], with all of them, except Vreeland et al. (who does not use time of initial surgery but time of margin-negative surgery as end-point), suggesting that the time from diagnosis to operative treatment of breast cancer has increased over the years, particularly with the advent of breast MRI [5, 26-29]. Although we did not evaluate the impact of preoperative breast MRI on surgical waiting time in our study, our results indicate that breast MRI exams are usually performed within a reasonable time frame following their initial request. Although this delay appears shorter in France, most of the preoperative breast MRI exams in both countries were performed within 3 weeks of their initial request $(75 \%$ in Québec, 99\% in France), which represents an acceptable delay according to the majority of French and Quebec respondents.

Limitations concerning our results that are inherent to survey-based methods must also be taken into account. First, there is always the possibility of selection bias with voluntary respondents who would be more likely to answer if they were particularly interested in the topic at hand. And given that our data collection was performed through an anonymous survey, we have no way of independently confirming or corroborating these selfreported answers. Second, to achieve an acceptable response rate, our questionnaire was also somewhat limited in its ability to precisely ascertain certain variables that may require in depth data collection, such as waiting time for a breast MRI, which was evaluated as an approximate range of weeks, rather than an exact number of days. Third, as our study only addresses pre-MRI waiting time (time from initial request to completion of the preoperative breast MRI examination), we cannot directly comment on the differences regarding preoperative surgical waiting time, which includes both the preMRI waiting time and the post-MRI waiting time (time from completion of breast MRI to actual surgery). Given that Zhang et al. have shown that differences in surgical waiting time were most attributable to post-MRI waiting time, due to post-MRI procedures and imaging (second look US and MRI-guided biopsies), this may be an interesting variable to evaluate in future studies given its reported decrease in patient quality of life from additional anxiety [5, 27, 30-32]. Finally, this survey was conducted in 2015-2016, and the responses could have changed over time.

\section{Conclusion}

Overall, our study demonstrates that both Quebec and France make effective use of breast MRI within the confines of their respective health systems. Most radiologists performing breast MRIs work in non-academic institutions and interpret 1-10 breast MRI exams per week. MRI-guided breast biopsies are not widely available in both countries. Quebec demonstrates a higher waiting time than France for breast MRI exams, but most of preoperative breast MRI are performed within 3 weeks in both countries. Of note is the importance of the surgeon's opinion influencing the recommendation of preoperative MRI in Quebec.

\section{Abbreviations \\ EBM: Evidence-Based Medicine; MRI: Magnetic resonance imaging; SCFR: Société Canadienne Française de Radiologie; SIFEM: Société d'Imagerie de la Femme}

\section{Acknowledgements}

The authors would like to thank Société Canadienne Francaise de Radiologie (SCFR) and Société d'Imagerie de la Femme (SIFEM) for advertising the link to our survey to their members.

\section{Authors' contributions}

The scientific guarantor of this publication is Benoit Mesurolle. Study concept and design: Benoît Mesurolle and Michelle Zhang. Literature research: Benoît Mesurolle, Simon Sun. Data analysis: Benoît Mesurolle, Simon Sun, Michelle Zhang. Moussa Keita kindly provided statistical advice for this manuscript. Manuscript preparation: Benoit Mesurolle, Simon Sun, Michelle Zhang. Manuscript edition: Simon Sun, Michelle Zhang. The authors read and approved the final manuscript.

\section{Funding}

The authors state that this work has not received any funding.

Availability of data and materials

Data are presented in the "Results" section (tables).

Ethics approval and consent to participate

This study was based on a survey among breast radiologists. Institutional Review Board approval was not required.

Consent for publication

The authors have approved the final article.

Competing interests

The authors have no conflicts of interest. 


\section{Author details}

'Centre République, ELSAN, 99 avenue de la République, BP 304, 63023 Clermont-Ferrand Cedex 2, France. ${ }^{2}$ Breast Clinic, McGill University Health Center, Royal Victoria Hospital, 1001 Decarie Boulevard, Montreal, QC H4A 3 J1, Canada.

Received: 2 February 2020 Accepted: 29 May 2020

Published online: 01 July 2020

\section{References}

1. Gilles R, Guinebretière JM, Lucidarme $O$ et al (1994) Nonpalpable breast tumors: diagnosis with contrast-enhanced subtraction dynamic MR imaging. Radiology 191:625-631

2. Lehman CD, DeMartini W, Anderson BO, Edge SB (2009) Indications for breast MRI in the patient with newly diagnosed breast cancer. J Natl Compr Cancer Netw 7:193-201

3. Tan S, David J, Lalonde L et al (2017) Breast magnetic resonance imaging: are those who need it getting it? Curr Oncol. 24(3):e205-e213

4. Parsyan A, Moldoveanu D, Balram B et al (2016) Influence of preoperative magnetic resonance imaging on the surgical management of breast cancer patients. Am J Surg. 211:1089-1094

5. Zhang M, Sun S, Mesurolle B (2017) The impact of pre-operative breast MRI on surgical waiting time. PLoS One 12:e0169756

6. Clauser P, Mann R, Athanasiou A et al (2018) A survey by the European Society of Breast Imaging on the utilisation of breast MRI in clinical practice. Eur Radiol 28:1909-1918

7. Adkisson CD, Vallow LA, Kowalchik $K$ et al (2011) Patient age and preoperative breast MRI in women with breast cancer: biopsy and surgical implications. Ann Surg Oncol 18(6):1678-1683

8. Deber RA (2003) Rekindling reform: lessons from Canada. Am J Public Health 93:20-24

9. Rodwin VG (2003) The health care system under French National Health Insurance: lessons for health reform. Am J Public Health 93:31-37

10. Thomassin-Naggara I, Jalaguier-Coudray A, Chopier J, Tardivon A, Trop I (2013) Current opinion on clip placement after breast biopsy: a survey of practising radiologists in France and Quebec. Clin Radiol 68:378-383

11. American College of Radiology (2013) Breast Imaging Center of Excellence Requirements https://www.acraccreditation.org/ /media/ACRAccreditation/ Documents/BICOE/BICOErequirements.pdf?la=en Accessed May 27, 2018

12. Bassett LW, Dhaliwal SG, Eradat J et al (2008) National trends and practices in breast MRI. AJR Am J Roentgenol 191:332-339

13. Houssami N, Turner R, Morrow M (2013) Preoperative magnetic resonance imaging in breast cancer: meta-analysis of surgical outcomes. Ann Surg 257: 249-255

14. Sackett DL, Rosenberg WM, Gray JA, Haynes RB, Richardson WS (1996) Evidence based medicine: what it is and what it isn't. BMJ 312(7023):71-72

15. Lee J, Tanaka E, Eby PR et al (2017) Preoperative breast MRI: surgeons' patient selection patterns and potential bias in outcomes analyses. AJR Am J Roentgenol 208:923-932

16. Boisserie-Lacroix M (2006) Disclosing a diagnosis of breast cancer: what is the role of the radiologist? J Radiol 87:105-108

17. Séradour B, Ancelle-Park R (2006) Breast cancer screening: are results of French and international programmes comparable? J Radiol 87:1009-1014

18. Dehn T (2008) Who should run breast clinics, surgeons or radiologists? Ann R Coll Surg Engl 90:187-192

19. Verheyden C, Pages-Bouic E, Balleyguier C et al (2016) Underestimation Rate at MR Imaging-quided Vacuumassisted Breast Biopsy: A Multi-Institutional Retrospective Study of 1509 Breast Biopsies. Radiology 281:708-719.

20. Plantade R, Thomassin-Naggara I (2014) MRI vacuum-assisted breast biopsies. Diagn Interv Imaging 95:779-801

21. Chopier J, Dratwa C, Antoine M, Gonin J, Thomassin Naggara I (2014) Radiopathological correlations: masses, non-masslike enhancements and MRl-guidedbiopsy. Diagn Interv Imaging 95:213-225

22. https://www.acraccreditation.org/ /media/ACRAccreditation/Documents/ Breast-MRI/Requirements.pdf Accessed May 27, 2018

23. Barua B (2017) Waiting Your Turn: Wait Times for Health Care in Canada, 2017 Report. https://www.fraserinstitute.org/studies/waiting-yourturn-waittimes-forhealth-care-in-canada-2017 Accessed July 31, 2018

24. Molinie F, Leux C, Delafosse P et al (2013) Waiting time disparities in breast cancer diagnosis and treatment: a population-based study in France. Breast 22(5):810-816
25. Plan Cancer 2014-2019. http://solidarites-sante.gouv.fr/MG/pdf/2014-02-03_ Plan_cancer-2.pdf Accessed July 30, 2018

26. Hulvat M, Sandalow N, Rademaker A, Helenowski I, Hansen NM (2010) Time from diagnosis to definitive operative treatment of operable breast cancer in the era of multimodal imaging. Surgery 148:746-750 discussion 50-51

27. Kothari A, Fentiman IS (2003) 22. Diagnostic delays in breast cancer and impact on survival. Int J Clin Pract 57:200-203

28. Bleicher RJ, Ciocca RM, Egleston BL et al (2009) Association of routine pretreatment magnetic resonance imaging with time to surgery, mastectomy rate, and margin status. J Am Coll Surg 209:180-187

29. Vreeland TJ, Berry Iv JS, Schneble E et al (2017) Routine pre-treatment MRI for breast cancer in a single-payer medical center: effects on surgical choices, timing and outcomes J Cancer 23; 8:2442-2448

30. Flory N, Lang EV (2011) Distress in the radiology waiting room. Radiology 260:166-173

31. Lang EV, Berbaum KS, Lutgendorf SK (2009) Large-core breast biopsy: abnormal salivary cortisol profiles associated with uncertainty of diagnosis. Radiology 250:631-637

32. Brocken P, Prins JB, Dekhuijzen PN, van der Heijden HF (2012) The faster the better?-A systematic review on distress in the diagnostic phase of suspected cancer, and the influence of rapid diagnostic pathways. Psychooncology 21:1-10

\section{Publisher's Note}

Springer Nature remains neutral with regard to jurisdictional claims in published maps and institutional affiliations.

\section{Submit your manuscript to a SpringerOpen ${ }^{\circ}$ journal and benefit from:}

- Convenient online submission

- Rigorous peer review

- Open access: articles freely available online

High visibility within the field

- Retaining the copyright to your article

Submit your next manuscript at $\boldsymbol{\nabla}$ springeropen.com 